\title{
ANALYSIS OF THE WAREHOUSE WORK ACCIDENTS IN LOGISTICS SECTOR
}

\section{DOI: 10.17261/Pressacademia.2019.1102 \\ PAP- V.9-2019(49)-p.262-268}

Gulsen Bas ${ }^{1}$, A. Murat Koseoğlu²

${ }^{1}$ Okan University, Tuzla Campus, Istanbul, Turkey.

bbgulsen@gmail.com; ORCID: 0000-0003-2597-1754

${ }^{2}$ Okan University, Tuzla Campus, Istanbul, Turkey.

murat.koseoglu@okan.edu.tr, ORCID: 0000-0003-4169-3678

\section{To cite this document}

Bas, G., Koeseoglu, A.M., (2019). Analysis of the warehouse work accidents in logistics sector. PressAcademia Procedia (PAP), V.9, p.262268

Permemant link to this document: http://doi.org/10.17261/Pressacademia.2019.1102

Copyright: Published by PressAcademia and limited licenced re-use rights only.

\begin{abstract}
Purpose- In this study, it is aimed to analyze the work accidents in storage activities which is one of the important functions of the logistics sector.

Methodology- In the scope of the study, 130 work accidents, which were reported by occupational safety experts in 2018 , were examined in a logistics company. Accidents are examined on a monthly basis according to the causes of the accidents, injured area, type of injury, the position of the personnel and the loss of days. Occupational diseases are not included in this review.

Findings- According to the data obtained from the study most of the accidents occurred in Istanbul. The common accidents are falling, crashing, jamming, falling of material, cutting of an object and accidents in in-depot traffic. Most of the injuries on hands and feet were caused by hard impacts. Individual reasons are the main reasons for accidents.

Conclusion- The logistics sector needs data, technology, and intensive labor force. The pressure of intense work, negligence, tiredness and the pressure to finish work bring work accidents. It is observed as the cause of accidents that the employees' individual attitudes, lack of education, inadequate training and employee negligence. It is concluded that occupational health and safety practices should be accepted in order to achieve a decrease in the accidents, training should be given to make behavioral changes for conducting operations, and a common occupational health and safety culture have to be established in the company with effective audits.
\end{abstract}

Keywords: Logistics, occupational health and safety, warehouse operations, work accidents.

JEL Codes: J28, J81, K32

\section{LOJISTIK SEKTÖRÜNDE DEPO IŞ KAZALARI ANALIZi}

\section{ÖZET}

Amaç- Bu çalışmada Lojistik sektörünün önemli fonksiyonlarından biri olan depolardaki iş kazalarının analizinin yapılması amaçlanmıştır. Yöntem- Araştırma kapsamında bir lojistik işletmesinde İş Sağlığı ve Güvenliği (iSG) Birimine bağlı iş güvenliği uzmanlarının 2018 yılında raporladığı 130 iş kazası incelenmiştir. İşletmedeki kazalar; kazaların nedenlerine, yaralanan bölgeye, yaralanma türüne, personelin pozisyonuna, gün kayıplarına ve ay bazında dağılımına göre incelenmiştir. Meslek hastalıkları bu incelemeye dâhil edilmemiştir.

Bulgular- İncelemeler sonucunda işletmede, en fazla iş kazası İstanbul'da yaşanmış. En sık karşılaşılan kazalar düşme, çarpma, sıkışma, malzemenin düşmesi, bir cismin kesmesi ve trafikte yaşanan kazalardır. En çok el ve ayaklarda sert darbe sonucu yaralanmalar oluşmuştur. Kazların temel sebebi bireysel nedenlerdir.

Sonuç- Lojistik sektörü bilgi, teknoloji ve yoğun emek gücüne ihtiyaç duymaktadır. Yoğun çalışma temposunun dikkatsizlik, yorgunluk ve işi yetiştirme baskısı iş kazalarını da getirdiği görülmektedir. Bu kazaların; genel olarak çalışanların bireysel tutumları, eğitim eksikliği, eğitimlerin yetersiz olması ve çalışan ihmallerinden kaynaklandığı görülmüştür. İş kazalarında düşüş sağlanması için iş sağlığı ve güvenliği uygulamalarının kabul görmesi, eğitimlerin davranışa dönüştürülecek yöntemlerle verilmesi, etkili denetimlerle işletmede ortak bir iş sağlığı ve güvenliği kültürü oluşturulması gerektiği sonucuna varılmıştır.

Anahtar Kelimeler: Depo operasyonları, iş kazası, iş sağlığı ve güvenliği, lojistik JEL Kodları: J28, J81, K32 


\section{GíRiş}

iş kazaları, beklenmedik olayların istenmeyen durumlarla sonuçlanmasıdır. iş kazaları sonucunda insanlar zarar örebilmekte, yaralanabilmekte hatta hayatlarını kaybedebilmektedir. Ürün ve makineler zarar görebilmekte bunun sonucunda da hizmetler ya da çalışmalar aksayabilmektedir (WHO, 1949) iş kazalarında sadece kaza geçiren çalışan etkilenmemektedir. Her iş kazası işleyişi aksatmakta, çalışanların motivasyonunu düşürmekte, verimliliği olumsuz etkilemektedir. Bu kazalara sistemli ve bilimsel yaklaşllarak çözümlenmesi, kazaların kök nedenlerinin bulunarak düzeltici önleyici tedbirlere doğru ve gerçekçi yaklaşııması, benzer kazaların bir daha yaşanmaması için hayati önem taşımaktadır. Sistematik yaklaşımla yapılan etkin ve verimli kök neden analizleri, iş sağlığı ve güvenliği politikalarının oluşturulması aşamasında veri olarak kullanılabilecektir. İş sağlı̆̆ı ve güvenliği politikasının oluşturulması için; bilgilerin elde edilmesi, değerlendirilmesi ve sonuç çıkarılarak çözüm üretilmesi, dayanakların bir araya getirilmesi yani iş kazası analizini gerektirmektedir.

\section{LITERATÜR TARMASI}

\subsection{Lojistik Sektörü}

Lojistik (fiziksel dağııım) konuları müşteri hizmetlerinden, stok kontrolüne, koruyucu paketlemeden, sipariş işlemeye kadar nakliye, depo yeri seçimi ve depolama gibi bir çok unsuru barındıran faaliyetlerden oluşur. (Boone and Kurtz, 1992, p.492, aktaran Volkan Peker Yüksek Lisans Tezi). Lojistik, ürünün üretim noktasından başlayarak, son kullanıcıya ulaşıncaya kadar geçen süreçteki farklı organizasyonlar arasındaki koordinasyon işidir.

ABD Lojistik Konseyine göre; Lojistik, müşterilerin gereksinimlerini karşılamak üzere ürünlerin üretildiği veya kaynaklandığı noktadan, son kullanııının bulunduğu tüketim noktasına kadar olan tedarik zinciri içindeki malzemelerin, servis hizmetlerinin ve bilgi akışının etkin ve verimli bir şekilde iki yöne doğru hareketinin ve depolanmasının, planlanması, uygulanması ve kontrol edilmesidir." (http://www.lojisturk.net/guncel/lojistik-tanimi-tarihsel-gelisimi-1341827844h.html - erişim tarihi 12.04.2019)

Lojistik; etnik kelime kökeni Latince'den gelen iki ayrı kelimeden oluşmaktadır. Bu kelimeler mantık anlamına gelen "logic" ile istatistik anlamında kullanılmış olan "statics"dir. Dolayısıyla lojistik aslında mantıklı hesap olarak ortaya çıkmıştır (Acar ve Köseoğlu, 2014: 3).

Tüm bu tanımlar ışı̆ı̆ında bir ürünün üretilmesinden tüketiciye ulaşana kadar zaman, verimlilik, yol ve maliyet hesaplarını da içeren sistematik bir süreçtir.

\subsection{Depo}

Depo; "ürünlerin ham madde aşamasından üretim ortamına, oradan da tüketim merkezlerine dağııımına kadar olan faaliyetler dizisinin gerçekleştirilmesinde stratejik rol oynayan ara noktalardır." (MEB, ULAŞTIRMA HiZMETLERI DEPO işLEMLERi, Ankara 2011) Üretim aşamasından dağııım aşamasına kadar yer alan tüm noktalarda depolar vazgeçilmez önem taşımaktadır. "Ayrıca uluslararası ticarette ithalat, ihracat ve gümrük süreçlerinde eşyaların muhafaza edildiği, stoklandığı, korunduğu ve taşımaya hazır hâle getirildiği açık veya kapalı alanlara gereksinim duyulmaktadır." (MEB, ULAŞTIRMA HiZMETLERI DEPO işLEMLERI, Ankara 2011)

Depo, müşteriye doğru ürünün, doğru zamanda sevkini sağlayarak, katma değer üretilen bir merkezdir. Depo, profesyonel bir yaklaşım ve sistematik çalışmayı gerektirir. Depo, müdüründen, ekipman operatörlerine, sevkiyat amirlerinden sistem operatörüne kadar insan kaynağıyla kalifiye işgücü gerektirir. (https://temesist.com/deponun-tanimi-2/ 12.04.2019)

\section{3.iş̧ Kazaları}

İşyerinde veya işin yürütümü nedeniyle meydana gelen, ölüme sebebiyet veren veya vücut bütünlüğünü ruhen ya da bedenen özre uğratan olay olarak tanımlamaktadır. (6331 Sayılı İ̧ Sağlığı ve Güvenliği Kanunu). Bir olayın iş kazası sayılabilmesi farklı şartlara bağlanmıştır. İs kazası Sigortalının işyerinde ya da Iş̧veren tarafından yürütülmekte olan iş nedeniyle görevli olarak işyeri dışında bedenen ya da ruhen özre sebep olan olaydır. Emziren kadın sigortalının çocuğuna süt vermek için ayrılan zamanlarda ve sigortalının işverence sağlanan bir taşıtla işin yapıllığı yere gidiş gelişi sırasında meydana gelen olaylar da iş kazası olarak değerlendirilmektedir. (5510 sayılı Sosyal Sigortalar Ve Genel Sağlık Sigortası Kanunu) Yapılan işin niteliği, çalışanın deneyimi ve riskler karşısındaki algısı, tutumu ile çalışma ortamının özelliği iş kazalarına sebep olan faktörlerin balında gelmektedir. Dünya sağlık örgütünün (WHO) tanımına göre; Sağlık, Bedensel, ruhsal ve sosyal yönden tam bir iyilik halidir. İşletmelerde insan sağıı̆ının korunması ve çalışanın evine zarar görmeden dönmesi için çeşitli önlemler alınmaktadır. "iş sağlı̆ı her meslekteki işçilerin fiziksel, ruhsal ve sosyal iyiliklerini en üst düzeyde koruma ve geliştirmeyi; iş̧̧ilerin çalışma koşullarından ötürü sağlıklarını kaybetmelerinin önlenmesini; işçilerin işyerindeki sağlığa zararlı faktörlerden kaynaklanan risklerden korunmasını; iş̧inin fiziksel ve psikolojik donanımına uygun işte çalışmasının sağlanmasını ve özetle işin insana uyarlanmasını ve her bir insanın işine adapte edilmesini amaçlar" (WHO, 2005; aktaran ÇASGEM http://www.casgem.gov.tr/dosyalar/kitap/117/dosya-117-5309.pdf). 11.04.2019) i̇ş güvenliğinin temel amacını, çalışanların işletme ve işin getirdiği tehlikelerden korumak, uygun olmayan çalışma şartlarının önlemler alınarak sağlıklı ve güvenli çalışma şartlarını oluşturmak için yapılan bilimsel çalışmalar oluşturur. İş güvenliği Çalışanların işletmelerde beden ve ruh sağlığının korunması için alınan her türlü tedbirdir. Ayrıca OHSAS 18001'de güvenlik sadece çalışanı korumaz aynı zamanda işletmeyi ve üretimi de koruma altına alacak şekilde tasarlanmışıı. (OHSAS 18001, 2007). Iş̧ yeri ortamından ya da çalışma şeklinden kaynaklı çalışanın sağlığında da bozulmalar olabilmektedir. Meslek hastalığı, sigortalının çalıştığı veya yaptığı işin niteliğinden dolayı tekrarlanan bir sebeple veya işin yürütüm şartları yüzünden uğradığı geçici veya sürekli hastalık, bedensel veya ruhsal özürlülük halleridir. (5510 Sayılı Sosyal Sigortalar ve Genel Sağlık Sigortası Kanunu) “işyerinde var olan ya da dışarıdan gelebilecek, çalışanı veya işyerini etkileyebilecek zarar veya hasar verme potansiyelidir."(6331 Sayılı İş Sağlığı ve Güvenliği Kanunu) 


\section{METODOLOJi}

Bu çalışmada lojistik sektöründe yer alan özel bir işletmenin 2018 yılı iş kazaları raporları araştırılmıştır. Raporlanan 130 iş kazasının kök neden analizleri kategorilere göre ayrılmıştır. İşletmede meydana gelen kazalar; kaza nedeni, kazanın aylara göre dağılımı, yaralanan bölge, yaralanma türü, pozisyon ve gün kayıplarına göre incelenmiştir. Meslek hastalıkları bu incelemenin dışında bırakılmıştır. Her kazanın kök neden analizi raporları ayrı ayrı değerlendirilmiş, kaza geçiren çalışanın eğitim durumu sorgulanmıştır. Kazalar nedenlerine, aylara, pozisyonlara, illere göre dağılımları grafikler haline getirilerek işletme özelinde yorumlanmıştır.

\section{BULGULAR}

Incelemeler sonucunda işletmede, en fazla iş kazası İstanbul'da yaşanmış, bu kazalara en çok depo personeli maruz kalmıştır. En sık karşılaşılan kazalar düşme, çarpma, sıkışma, malzemenin düşmesi, bir cismin kesmesi ve trafikte yaşanan kazalardır. En çok yaralanan bölge el ve ayaklarda künt darbe sonucu oluşmuştur. Bu kazların temel sebebi bireysel nedenlerdir. Aşağıda grafiksel olarak açıklanmıştır.

\subsubsection{Yılı İş Kazaları Analizi / Aylara Göre Dağılım}

Aylara göre iş kazaları incelendiğinde Şubat ayında 15 iş kazası yaşanmıştır. Nisan ayında 14, Ocak ayında da 13 kaza yaşanmıştır. En az iş kazası Eylül ayında, 2 tane olmuştur.

Grafik 1: İş Kazalarının Aylara Göre Dağıımı

\section{Aylara Göre Dağılım}

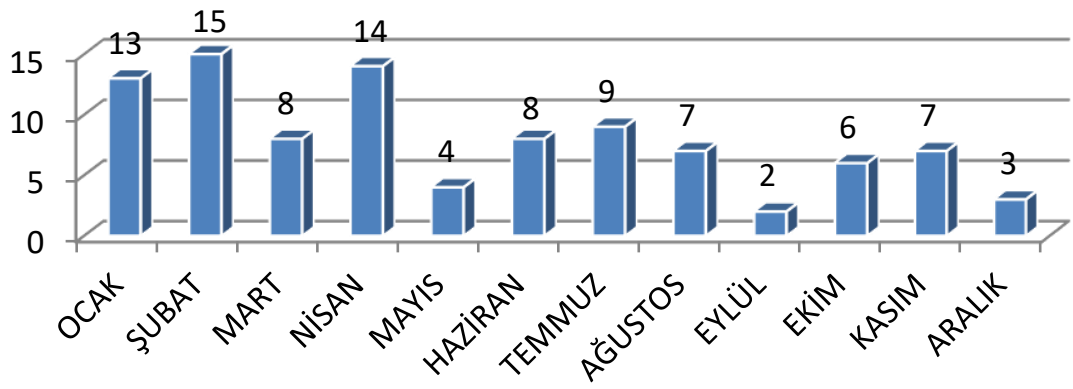

\subsubsection{Yılı İş Kazaları Analizi / ì Bazında Dağılım}

Lojistik sektöründe yer alan bu firmanın illere göre kaza sayısı incelendiğinde en fazla kaza sayısının İstanbul'da olduğu tespit edilmiştir. Yapılan çalışmalarda İstanbul'da çalışan personel sayısının fazla olması ve en fazla iş hacminin yine İstanbul ilinde olduğu belirlenmiştir (Grafik 2). İstanbul'u ana dağıtım merkezi olması, buradaki iş temposunu artırmaktadır.

Grafik 2: İ̧̧ Kazalarının illere Göre Dağııımı

\section{il Bazında Dağılım}

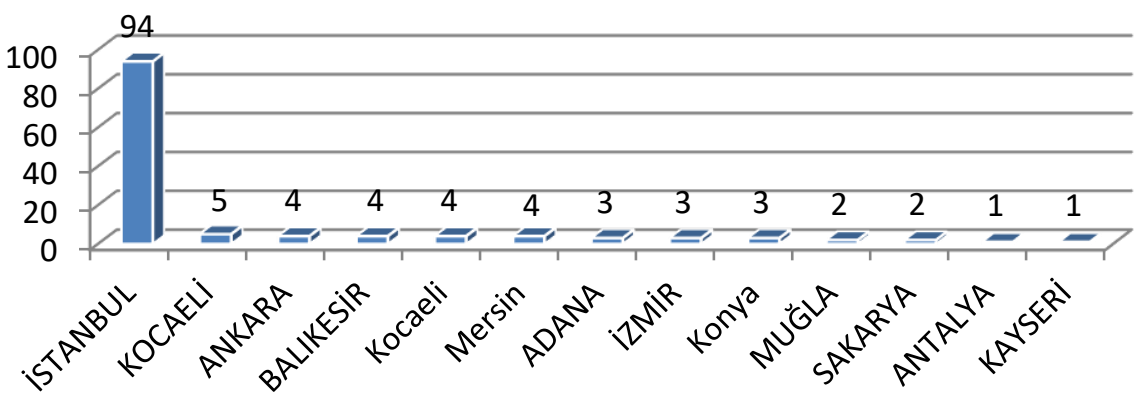




\subsubsection{Yılı İ̧̧ Kazaları Analizi / Kaza Sebepleri}

Kaza sebepleri incelendiğinde, 26 personelin düşme, 21 personelin çarpma, çarpışma ve 18 personelin de sıkışma/ezilme sonucu iş kazası geçirdiği görülmüştür.

Grafik 3: İ̧̧ Kazaları Sebepleri

\section{Kaza Sebebi}

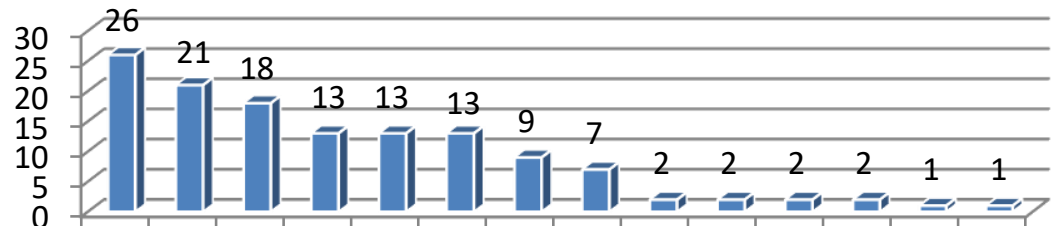

Kaza Sayıs

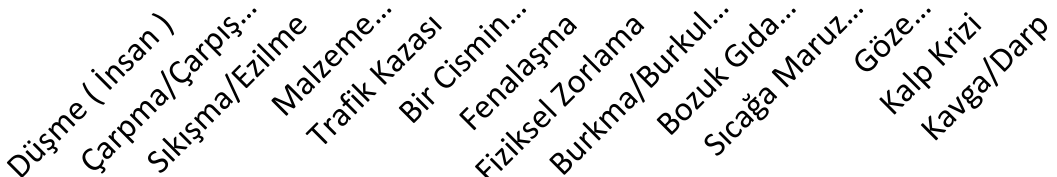

\subsubsection{Yılı İş Kazaları Analizi / Kök Neden Analizleri}

İş kazalarının kök neden analizleri incelendiğinde, kazaların en çok kişiye bağı eğitim eksikliği, davranışları, yeterlilik ve kabiliyetlerinden kaynaklandığı görülmüştür. Prosedürlere ve çalışma talimatlarına uymama ise 2. sırada yer almaktadır. Risk azaltma tedbirleri, tesis tasarım ve planlama, muhakeme ve değerlendirme eksiklikleri diğer nedenler olarak sıralanmaktadır.

Grafik 4: İş Kazaları Kök Neden Analizi

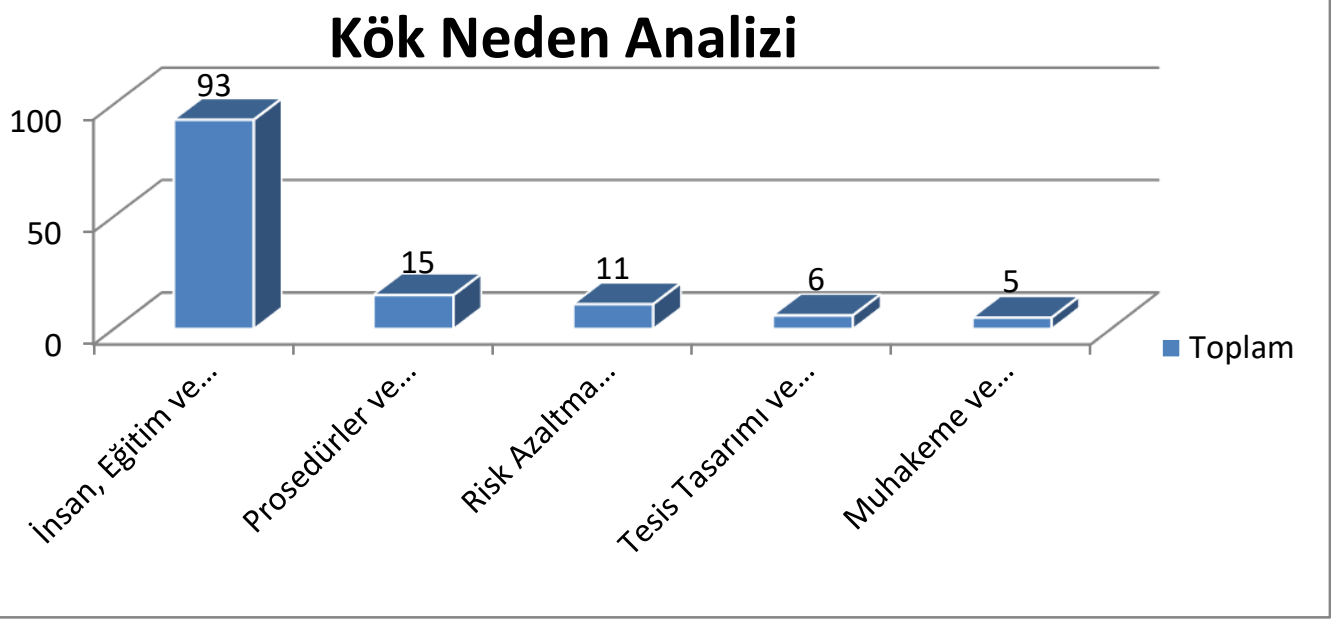

\subsubsection{Yılı İs Kazaları Analizi / Yaralanma Türü ve Yaralanan Bölge}

Depolarda emek gücüyle çalışmanın yoğun olması ve iş temposu nedeniyle künt darbe yaralanmaları ve yumuşak doku zedelenmesi yaralanma türlerinin başında gelmektedir. En fazla el ve bilekler kaza sonucu yaralana uzuvlar içerisindedir. 2. sırada dirsek ve kollar yer alırken sırasıyla göğüs, baş, dolaşım sistemi, omuz ve batın başlıca yaralanma bölgelerini oluşturmaktadır. 
Grafik 5. A: Yaralanma Türü

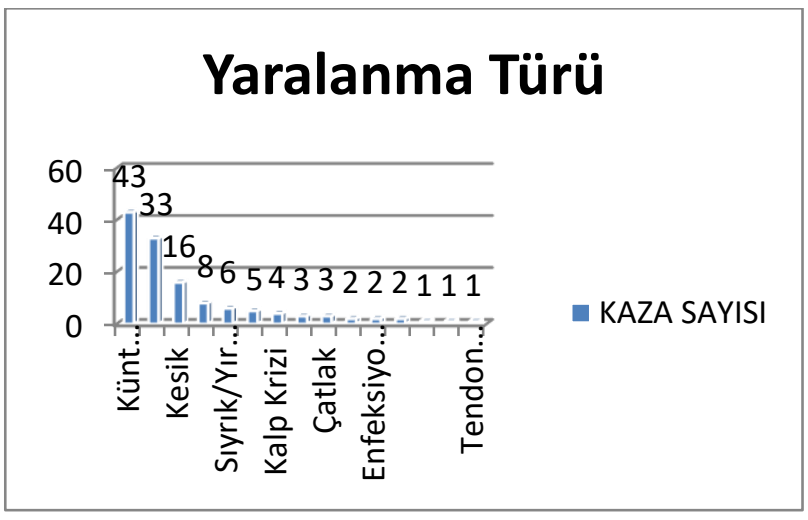

Grafik 5. B: Yaralanan Bölge

\section{Yaralanan Bölge}

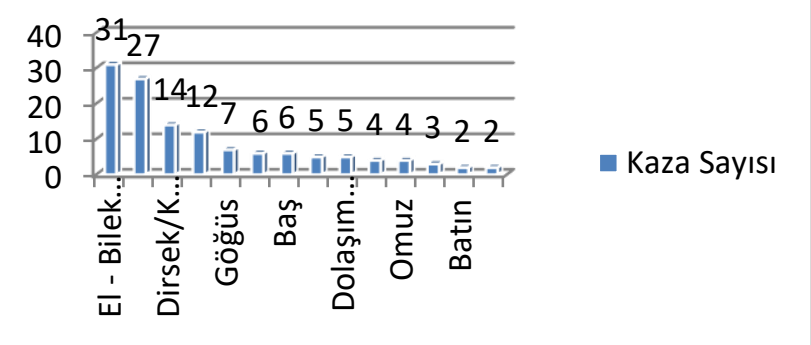

\subsubsection{Yılı İ̧̧ Kazaları Analizi / Pozisyon Bazında Dağılım}

En fazla iş kazasına depo personeli maruz kalmıştır. Yurt içi sürücülerinin trafikte karşılaştıkları kazalar ikinci sırada yer alırken, beyaz yaka üçüncü sırada yer almaktadır. Yurt dışı sürücüleri en az kazaya maruz kalan personel grubunda yer almaktadır.

Grafik 6: Personelin Görev Dağılımı

\section{Personelin Görevine Göre Dağılım}

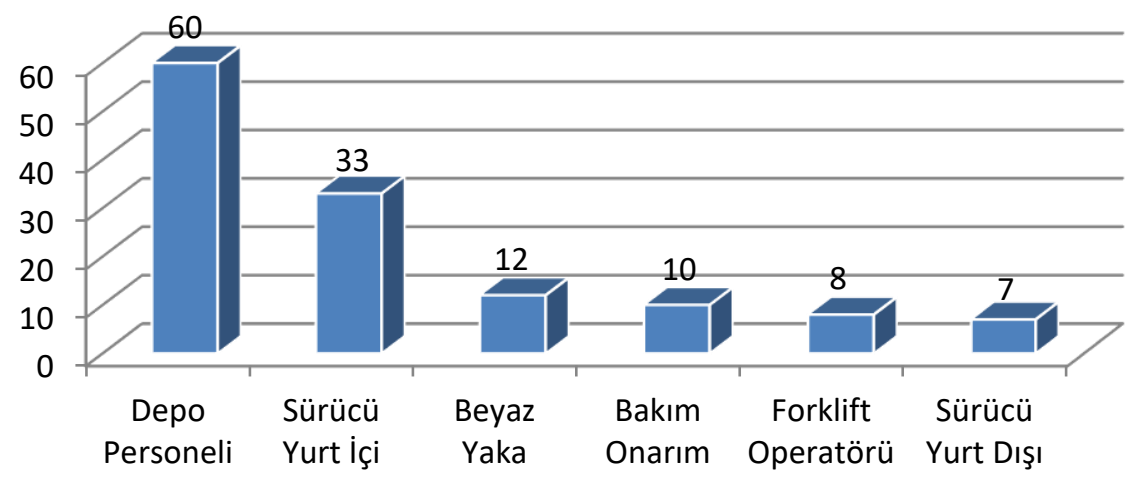

- Kaza Sayısı 


\subsubsection{Yılı İ̧ Kazaları Analizi / Gün Kayıplarına Göre Dağııım}

İlk yardımlı iş kazaları sayısının sektörde fazla olduğu, 3 gün kayıplı iş kazalarının da 2. Sırada yer aldığı tespit edilmiştir. İş kazalarında kaza etki derecesi büyüdükçe kişi bazlı iş günü kaybı da buna paralel olarak artmaktadır.

Grafik 7: Gün Kaybına Göre Kaza Sınıflar

\section{Gün Kaybına Göre Kaza Sınıfı}

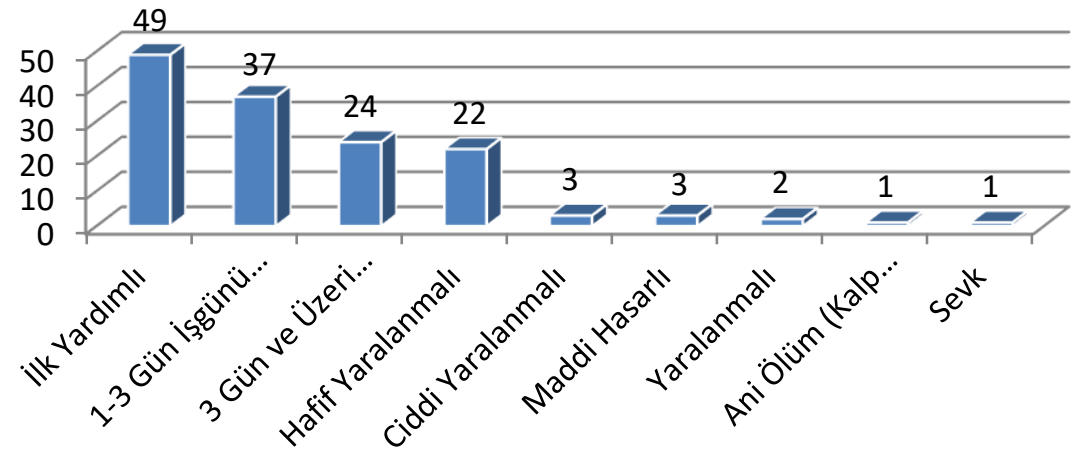

\subsubsection{Yılı İ̧ Kazaları Analizi / Olay Yerine Göre}

Depolama alanında yaşanan iş kazaları sayısı, tüm iş kazaları sayısının yarısı kadardır. En fazla iş kazası depo alanında yaşanmaktadır. Depo alanında kullanılan kaldırma-iletme ekipmanları, bu kazaları tetiklemektedir. Yanlış yapılan taşıma, dikkatsizlik, eğitim eksikliği ve ekipmanın yanlış kullanımı, bu kazaların en önemli sebeplerindendir.

Grafik 8: Olay Yerine Göre İş Kazaları

\section{Olay Yerine Göre}

60

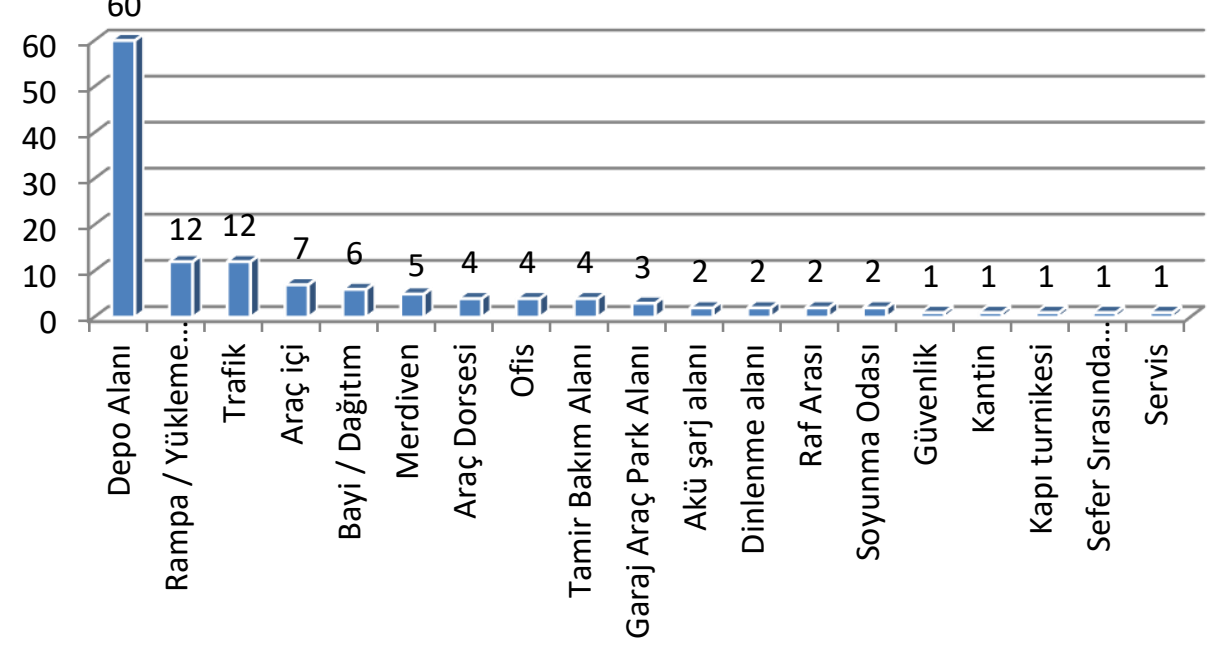

Toplam 


\section{SONUÇ}

Lojistik sektörü bilgi, teknoloji ve otomasyonunla birlikte beden gücüne de ihtiyaç duyan faaliyetleri içermektedir. İş kazalarına bakış ve kazaların azaltılmasına yönelik yapılan çalışmalar, hem iş gücü maliyetlerinin azaltılması, personel motivasyonunu sağlanması, üretkenlik ve verimliliğin artmasına hem de şirketin prestijine önemli katkılar sağlamaktadır. Bu çalışmada lojistik sektöründe yer alan özel bir işletmenin 2018 yılı iş kazaları verileri dikkate alınmıştır. Bu kazalarının sebepleri ağırlıklı olarak çalışanların tutumları, alışkanlıkları, eğitim eksikliği, ihmalleri ve talimatlara uymamasından kaynaklandığı görülmüştür. Bu bileşenler de iş güvenliğinin bir kültür olarak gelişmediğini göstermektedir. Bu işletmede yaşanan kazalarının önemli bir bölümü kişisel hataların düzeltilmesi ve etkili eğitim planı ile minimuma indirilmesi sağlanabilir. Çalışanlara etkili eğitimlerin verilmesi, isG kültürünün yaygınlaştırılması için çalışmalar yapılması ve denetimlerin arttırılması, iş güvenliği talimatlarına uyum sürecini hızlandırmak için ödül sisteminin kurulması iş kazalarının önlenmesinde etkili olacaktır. İ̧̧ kazalarındaki azalma, iş yerindeki güvenli çalışma nedeni ile verimliliği artıracak ve çalışana da motivasyon sağlayacaktır. Çalışanlarda farkındalık oluşturulması ve algı seviyelerinin arttırılması için; iş güvenliği ve meslek içi eğitimlerinin belirli aralıklarla tekrarlanmalı, özellikle davranış değiştirmeye yönelik eğitimlere yer verilmelidir. Böylece hem çalışanların iş sağlığı ve güvenliği sistemine katkı sağlayacak hem de iş güvenliği konusunda bir kültür oluşturulabilecektir. Ayrıca, geri bildirim sisteminin kurulması, çalışma alanındaki risk ve tehlikelerin çalışanlarla birlikte değerlendirilerek tedbirlerin alınması, bir kontrol mekanizmasının süreklilik içerecek şekilde işletilmesi gibi unsurların sağlanması iş kazalarının oluşumunu azaltacaktır. İşgücü kayıpları engellenecek, firma itibarı korunacaktır. Çalışanda şirketine karşı güven duygusu ve firmaya karşı sadakat sağlanarak hem performans hem de verimlilik artacaktır. Bu da rekabet avantajı ile işin doğru zamanda müşteriye minimum maliyetlerde ulaştırılmasına katkı sağlayacaktır.

\section{KAYNAKLAR}

Acar, Z., Köseoğlu, M. (2014). Lojistik Yaklaşımıyla Tedarik Zinciri Yönetimi. Nobel Yayıncılık, 1.Basım, Ankara.

Blanchard, Benjamin S. “Logistics Engineering And Management”, Prentice-Hall, 4tl Edition, 1992, P.3

Boone, Louis E. And KURTZ, David L. “Contemporary Marketing”, The Dryden Press International Edition, 7th Edition, 1992, P:492)

Bowersox, Donald J. And CLOSS, David J. “Logistical Management: The Integrated Supply Chain Process”, Mcgraw-Hill, 1996, P: 4

Ohsas, 18001, 2007, Occupational Health And Safety Management Systems, British Standarts Institute.

Topuzoğlu, İ. Ve Orhun, H., 1993. Türk Tabipleri Birliği, İş Hekimliği Ders Notları, Türk Tabipleri Birliği Yayını, Üçüncü Basım, Maya Matbaacılık, Ankara,

WHO, 1950. Annual Report Of The Director -General To The World Health Assembly And To The United Nations, WHO Publications, (25).

5510 Sayılı Sosyal Sigortalar Ve Genel Sağlık Sigortası Kanunu

6331 Sayılı İş Sağlığı Ve Güvenliği Kanunu

Http://Www.Megep.Meb.Gov.Tr/Mte_Program_Modul/Moduller_Pdf/Depo\%20\%C4\%B0\%C5\%9Flemleri.Pdf - Erişim Tarihi 22.04.2019

Https://Temesist.Com/Deponun-Tanimi-2/ 12.04.2019

WHO, 2005; Aktaran ÇASGEM Http://Www.Casgem.Gov.Tr/Dosyalar/Kitap/117/Dosya-117-5309.Pdf). Erişim Tarihi 11.04.2019)

Http://Www.Lojisturk.Net/Guncel/Lojistik-Tanimi-Tarihsel-Gelisimi-1341827844h.Html - Erişim Tarihi 12.04.2019)

MEB, ULAŞTIRMA HIZMETLERI DEPO işLEMLERI, Ankara 2011

Https://Temesist.Com/Deponun-Tanimi-2/ Erişim Tarihi 12.04.2019

WHO, 2005; Aktaran ÇASGEM Http://Www.Casgem.Gov.Tr/Dosyalar/Kitap/117/Dosya-117-5309.Pdf Erişim Tarihi 11.04.2019 